Supplementary Information

\title{
Biophysical and Structural Characterization of a Robust Octameric $\beta$-Peptide Bundle
}

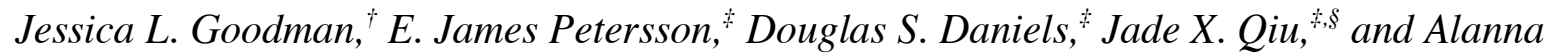

$$
\text { Schepartz }
$$

Departments of Molecular Biochemistry and Biophysics, Chemistry and Molecular, Cellular and Developmental Biology, Yale University, New Haven, Connecticut 06520-8107

General Methods. Fmoc-protected amino acids, $O$-Benzotriazole- $N, N, N$ ' $N$ '-tetramethyluronium-hexafluoro-phosphate (HBTU), $N$-hydroxybenzotriazole (HOBt), and Wang resin were purchased from Novabiochem (San Diego, CA). Dimethylformamide (DMF), N-methyl-2pyrrolidone (NMP), $N$-methyl morpholine (NMM), trifluoroacetic acid (TFA) and piperdine (Pip) were purchased from American Bioanalytical (Natick, MA). N-Fmoc- $\beta^{3}$-piodohomophenylalanine was purchased from Peptech (Burlington, MA). All other reagents were purchased from Sigma-Aldrich (St. Louis, MO). Mass spectra were acquired with an Applied Biosystems Voyager-DE Pro MALDI-TOF mass spectrometer (Foster City, CA). Reverse-phase HPLC was performed using a Varian Prostar HPLC and Vydac analytical (C8, $300 \AA$ A, $5 \mu \mathrm{m}, 4.6$ $\mathrm{mm} X 150 \mathrm{~mm})$ or preparative $(\mathrm{C} 8,300 \AA ̊ 丿, 5 \mu \mathrm{m}, 25 \mathrm{~mm} \mathrm{X} 250 \mathrm{~mm})$ columns, using water/acetonitrile gradients containing $0.1 \%$ TFA. Circular dichroism (CD) spectra were acquired with a Jasco J-810 Spectropolarimeter (Jasco, Tokyo, Japan) equipped with a Peltier temperature control. Analytical ultracentrifugation (AU) was performed using a Beckman XL-I 
instrument. Differential scanning calorimetry experiments were performed on a Microcal VPDSC instrument (Northhampton, MA) in the labs of Dr. Jeff Hoch at the University of Connecticut Health Center (Farmington, CT). ${ }^{1} \mathrm{H}$ NMR experiments were performed on a Bruker $500 \mathrm{MHz}$ instrument. All experiments were performed in phosphate buffer $\left(10 \mathrm{mM} \mathrm{NaH} \mathrm{PO}_{4}\right.$, $200 \mathrm{mM} \mathrm{NaCl}, \mathrm{pH}$ adjusted to 7.1 with $\mathrm{NaOH})$, except as noted.

$\beta$-peptide synthesis and purification. $\beta^{3}$-peptides were synthesized on a $25 \mu$ mole scale using standard Fmoc chemistry and Wang resin loaded with $\beta^{3}$-homoaspartic acid as previously described. ${ }^{1}$ One cycle of peptide elongation consisted of the following steps: First, the loaded resin was washed with DMF (6 X $30 \mathrm{sec})$ and the terminal Fmoc protecting group removed with 20\% Pip in DMF (1 X 2 min, 2 X 8 min). This deprotection step was supplemented with a second deprotection step using diazabicyclo[5.4.0]undec-7-ene (DBU) after five residues have been attached to the resin ( 1 X 2 min 20\% Pip/DMF, 2 X 8 min 20\% Pip/DMF, 1 X 8 min 2:2:96 Pip/DBU/DMF, and 1 X 8 min 20\% Pip/DMF). After deprotection, the resin was washed with DMF (6 X $30 \mathrm{sec}$ ) and the next $\beta^{3}$-amino acid coupling reaction was carried out for 30 min using 2 equiv. of the appropriate $\beta^{3}$-amino acid, 1.8 equiv. HBTU, 2 equiv. HOBt, and 5 equiv. diisopropylethylamine (DIEA). This coupling was the repeated with fresh reagents for another 30 min. The resin was then washed with DMF $(6$ X $30 \mathrm{sec})$ before the next cycle of elongation. This elongation cycle was repeated until the $\beta$-peptide sequence was complete. Once the final Fmoc protecting group had been removed, the resin was washed with DMF ( 8 X $30 \mathrm{sec})$ and methylene chloride ( 8 X $30 \mathrm{sec}$ ), dried for 20 min under nitrogen, and treated with a cleavage cocktail composed of $1 \% \mathrm{v} / \mathrm{v}$ each of water, triisopropylsilane and phenol in TFA ( 2 X $60 \mathrm{~min}$ ). The cleaved peptides were precipitated with $50 \% \mathrm{v} / \mathrm{v}$ pentane/ether. After decanting the ether 
and drying with nitrogen, the precipitated peptides were dissolved in $30 \% \mathrm{v} / \mathrm{v}$ acetonitrile in water and purified by HPLC.

The success of each synthesis was assessed by both HPLC and MALDI-TOF analysis of the crude reaction mixture. $\beta$-peptides were then purified to homogeneity by reverse-phase HPLC. The identities and purities of the purified $\beta$-peptides were assessed by analytical HPLC and mass spectrometry. MALDI mass spectra were obtained using peptide samples in -cyano4-hydroxycinnaminic acid (CHCA) matrix. The masses found were: Acid-1Y (m/z observed, calculated): $[\mathrm{M}+\mathrm{H}]^{+} 1685,1683 ;$ Acid-1Y* $(\mathrm{m} / \mathrm{z}$ observed, calculated $):[\mathrm{M}+\mathrm{H}]^{+} 1794,1793$ (Figure S1). Following purification, $\beta$-peptides were lyophilized and reconstituted in buffer (previously described) for characterization.

\section{Acid-1Y}

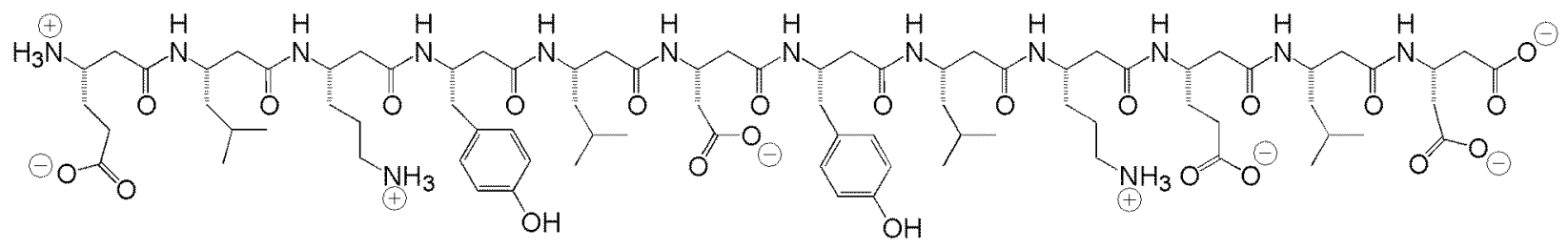

\section{Acid-1Y*}

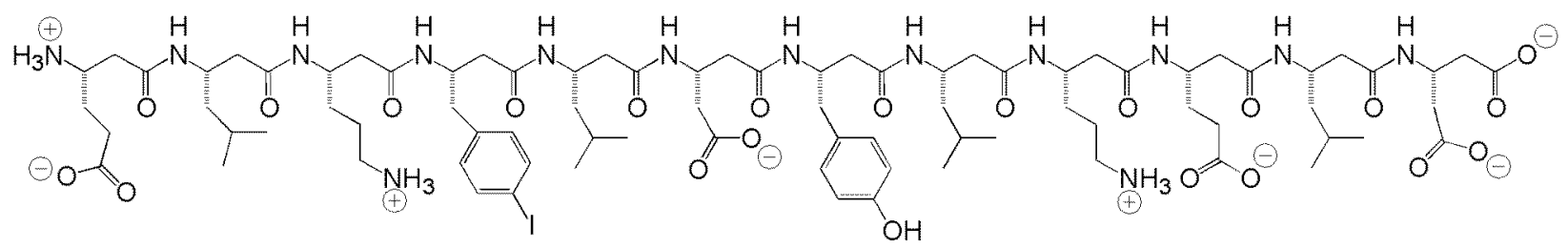

Figure S1. Chemical structures of Acid-1Y and Acid-1Y*.

Sedimentation Equilibrium Analytical Ultracentrifugation. HPLC-purified, lyophilized samples of Acid-1Y (300 $\mu \mathrm{M}, 150 \mu \mathrm{M}$ and $75 \mu \mathrm{M})$ and Acid-1Y* $(280 \mu \mathrm{M}, 140 \mu \mathrm{M}$ and 70 $\mu \mathrm{M})$ were resuspended and centrifuged at $25^{\circ} \mathrm{C}$ to equilibrium at three different speeds $(42,000$, 
50,000 and 60,000 rpm). Centrifugation was performed in an AN 60-Ti 4-hole rotor equipped with six-channel, carbon-epoxy composite centerpieces (Beckman). Absorbance was monitored at $280 \mathrm{~nm}$. Data were collected with a step size of $0.001 \mathrm{~cm}$ with scans occurring at $3 \mathrm{~h}$ intervals. Samples were determined to have reached equilibrium when no significant changes in radial concentration were observed in three successive scans using the program Match within the Heteroanalysis software suite (available from the National Analytical Ultracentrifugation Facility website, http://vm.uconn.edu wwwbiotc/uaf.html). The partial specific volume of each $\beta$-peptide was calculated from functional group composition according to Durchschlag and Zipper. ${ }^{2}$ The data was fit to a monomer- $n$-mer equilibrium model using the Heteroanalysis software. Fixed parameters: Acid-1Y monomer MW $=1682 \mathrm{Da}, \mathrm{v}-\mathrm{bar}=0.7846 \mathrm{~cm}^{3} / \mathrm{g}, \mathrm{d}=1.00674 \mathrm{~g} / \mathrm{mL}, \varepsilon_{280}=$ $1360 \mathrm{M}^{-1} \cdot \mathrm{cm}^{-1}$, and $\mathrm{n}=8$; Acid-1Y* monomer $\mathrm{MW}=1792 \mathrm{Da}, \mathrm{v}-\mathrm{bar}=0.7513 \mathrm{~cm}^{3} / \mathrm{g}, \mathrm{d}=$ $1.00674 \mathrm{~g} / \mathrm{mL}, \varepsilon_{280}=1360 \mathrm{M}^{-1} \bullet \mathrm{cm}^{-1}$, and $\mathrm{n}=8$. Fitted parameters: Acid-1Y $\ln K_{\mathrm{a}}=83.3 \pm 1.8$, RMSD $=0.01002$ and baseline deviation $<0.02 ;$ Acid $-1 Y^{*} \ln K_{\mathrm{a}}=65.6 \pm 0.1, \mathrm{RMSD}=0.00708$ and baseline deviation $<0.02$. The data shown was fit with these parameters and the resulting residuals. 

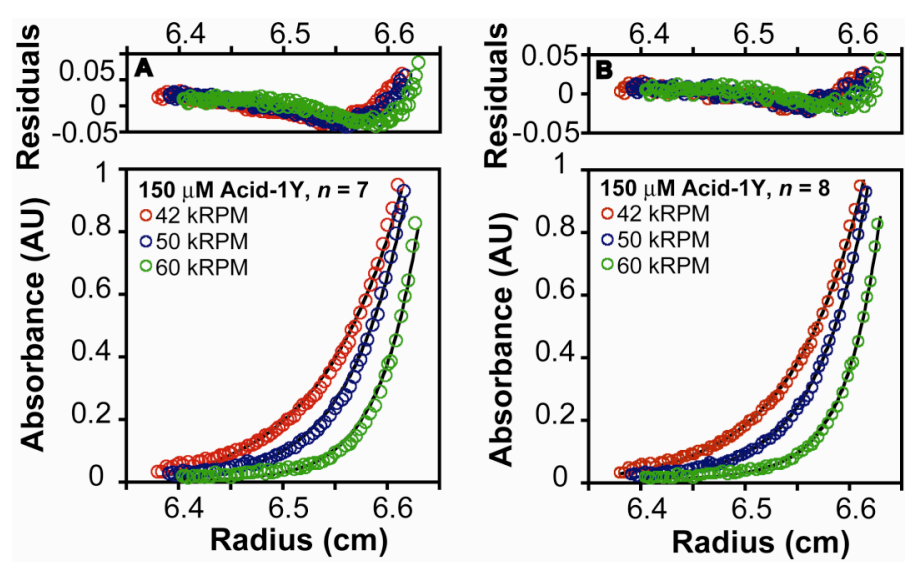

Figure S2. Acid-1Y self-association monitored by analytical ultracentrifugation (AU) $(150 \mu \mathrm{M}$ Acid$1 Y)$ and fit to monomer- $n$-mer equilibria where (A) $n=7$; (B) $n=8$; (C) $n=9$; and (D) $n=10$. Samples were prepared in 10
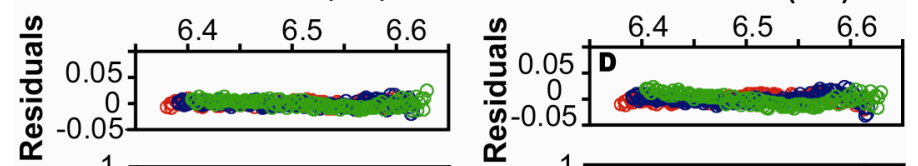
$\mathrm{mM} \mathrm{NaH} \mathrm{PO}_{4}, 200 \mathrm{mM} \mathrm{NaCl}(\mathrm{pH} 7.1)$ and centrifuged to equilibrium at $25{ }^{\circ} \mathrm{C}$ at
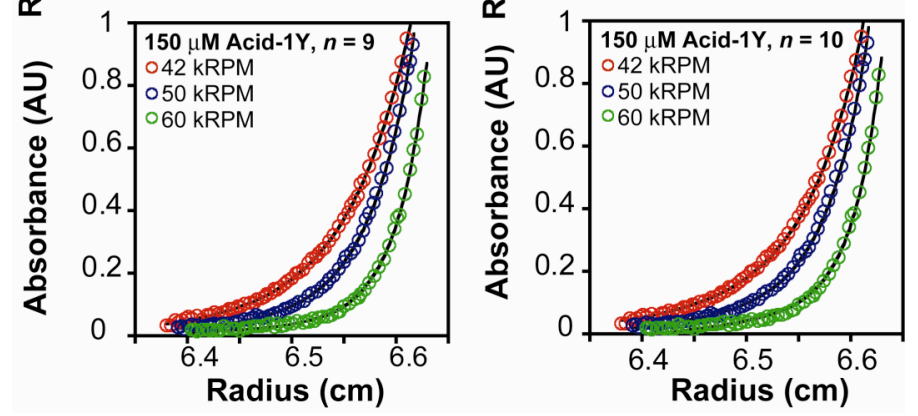
speeds of 42 (red), 50 (green), or 60 (blue) kRPM. The experimental data points are shown as open circles; lines indicate $\mathrm{a}$ fit to a monomer-octamer

model as described in the experimental section. We note that the data fit poorly to a monomerhexamer model $(n=6)$, with a RMSD significantly higher (0.2159) than the RMSD values for other fits including $n=7$ (0.01367), $n=8(0.00706)$ and $n=9(0.01370)$.

Circular Dichroism (CD). Wavelength dependent CD spectra were acquired for various concentrations of Acid-1Y and Acid- $1 \mathrm{Y}^{*}$ at $25{ }^{\circ} \mathrm{C}$ in continuous scan mode with $0.5 \mathrm{~nm}$ data pitch, $50 \mathrm{~nm} / \mathrm{min}$ scanning speed, $4 \mathrm{sec}$ response, $0.5 \mathrm{~nm}$ band width and 3 accumulations. The concentration dependence of the molar residue ellipticity (MRE) at $205 \mathrm{~nm}$ was determined by least-squares fitting of the total peptide monomer concentration as a function of experimental MRE with the following equation in Kaleidagraph (Synergy Software; Reading, PA) ${ }^{3}$ : 


$$
[\text { Peptide }]_{\text {Total }}=\left\{\frac{\left(\mathrm{MRE}_{\mathrm{Exp}}-\mathrm{MRE} \mathrm{Mon}_{\mathrm{Mon}}\right)\left(1 / \mathrm{K}_{\mathrm{a}}\right)}{n\left(\mathrm{MRE}_{\mathrm{Nmer}}-\mathrm{MRE}_{\mathrm{Mon}}\right)\left[1-\left(\frac{\left(\mathrm{MRE}_{\mathrm{Exp}}-\mathrm{MRE}_{\mathrm{Mon}}\right)}{\left(\mathrm{MRE}_{\mathrm{Nmer}}-\mathrm{MRE}_{\mathrm{Mon}}\right)}\right)\right]^{n}}\right\}^{1 /(\mathrm{n}-1)}
$$

The values obtained for the Acid-1Y fitted parameters were $\mathrm{MRE}_{\mathrm{Mon}}=11160 \mathrm{deg} \cdot \mathrm{cm}^{2} \cdot \mathrm{dmol}^{-1}$ (constant, not fit in equation), $\mathrm{MRE}_{\mathrm{Nmer}}=24900 \pm 180 \mathrm{deg} \bullet \mathrm{cm}^{2} \cdot \mathrm{dmol}^{-1}$, and $\ln K_{\mathrm{a}}=82.5 \pm 1.8$. The curve in Figure 2B was fit using these parameters. Wavelength-dependent CD spectra for Acid-1Y* also shows a concentration dependent increase in helical structure (Figure S3), analogous to that observed for Acid-1Y. The values obtained for the Acid-1Y* fitted parameters for a monomer-octamer model were $\mathrm{MRE}_{\mathrm{Mon}}=0 \mathrm{deg} \cdot \mathrm{cm}^{2} \cdot \mathrm{dmol}^{-1}$ (constant, not fit in equation), $\mathrm{MRE}_{\mathrm{Nmer}}=16755 \pm 58 \mathrm{deg} \bullet \mathrm{cm}^{2} \bullet \mathrm{dmol}^{-1}$, and $\ln K_{\mathrm{a}}=81.1 \pm 0.8$. However, analyses of $\mathrm{MRE}_{208}$ as a function of [Acid-1Y*] were ambiguous in discriminating between monomer-hexamer and monomer-octamer models. To resolve this ambiguity in favor of the monomer-octamer model

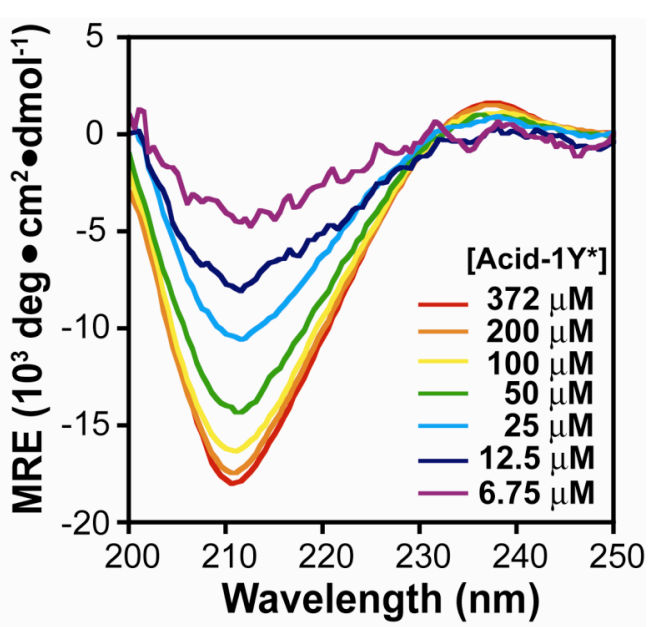

we used the results of the AU data and the crystal structure.

Figure S3. Acid-1Y* self-association measured by circular dichroism spectroscopy (CD). Wavelengthdependent CD spectra of Acid-1Y* at the indicated [Acid-1Y*]. 
Temperature-dependent CD spectra were obtained at $205 \mathrm{~nm}$ between 5 and $95{ }^{\circ} \mathrm{C}$, using the variable temperature module provided with the instrument. Data were collected with a $1{ }^{\circ} \mathrm{C}$ data pitch, $5 \mathrm{sec}$ delay time, $1{ }^{\circ} \mathrm{C} / \mathrm{min}$ temperature slope, $4 \mathrm{sec}$ response time, and $1 \mathrm{~nm}$ band width. The first derivatives of the temperature-dependent CD spectra for the various concentrations of Acid-1Y were calculated and the $\mathrm{T}_{\mathrm{m}}$ values reported correspond to the maximum of the $\delta \mathrm{MRE}_{205} / \delta \mathrm{T}$ plots. Refer to Figure $3 \mathrm{~A}$ for a plot of the $\delta \mathrm{MRE}_{208} / \delta \mathrm{T}$ as a function of temperature for Acid-1Y.

1-anilino-8-naphthalenesulfonate (ANS) Binding. Stock solutions of $400 \mu \mathrm{M}$ Acid-1Y were prepared in $10 \mathrm{X}$ PBC (100 mM phosphate, borate, and citrate) supplemented with $200 \mathrm{mM}$ $\mathrm{NaCl}, \mathrm{pH} 7.0$; a $10 \mu \mathrm{M}$ stock of ANS was prepared in the same buffer (from an initial stock of $20 \mu \mathrm{M}$ ANS in $10 \mathrm{X}$ PBC). Binding reactions were performed by mixing $80 \mu \mathrm{L}$ of the ANS solution with an appropriate volume of the Acid-1Y stock solution and diluting to a final volume of $160 \mu \mathrm{L}$ with $10 \mathrm{X} \mathrm{PBC}, 200 \mathrm{mM} \mathrm{NaCl}$ in order to produce $400,200,100,50$ and $25 \mu \mathrm{M}$ solutions of Acid-1Y. Fluorescence intensity (counts/s) measurements were made using a Photon Technology International (Lawrenceville, NJ) Quantamaster C-60 spectrofluorimeter at $25{ }^{\circ} \mathrm{C}$ in a $1 \mathrm{~cm}$ path length Hellma (Mullheim, Germany) cuvette. The sample was excited with $350 \mathrm{~nm}$ light (4 $\mathrm{nm}$ slit width) and fluorescence emission was measured at $1 \mathrm{~nm}$ intervals between 400 and $600 \mathrm{~nm}$. ANS binding was not performed on Acid-1Y*.

Differential Scanning Calorimetry. Temperature scans were performed from 5 to $125^{\circ} \mathrm{C}$ at a scan rate of $1{ }^{\circ} \mathrm{C} / \mathrm{min}$. with a $10 \mathrm{~min}$. equilibration period at 5 and $125{ }^{\circ} \mathrm{C}$. All scans were performed with an excess pressure of 40 PSI. Samples of $300 \mu \mathrm{L}$ (142 $\mu \mathrm{L}$ sample cell) were injected from the autosampling tray after being held at $10{ }^{\circ} \mathrm{C}$. The raw data of temperature, power and time were converted to plots of heat capacity versus temperature. This data was fit to 
a two-state model with dissociation of eight subunits using the program EXAM. ${ }^{4}$ This process involves fitting $\Delta \mathrm{H}_{\mathrm{Cal}}\left(\mathrm{T}_{1 / 2}\right), \Delta \mathrm{C}_{\mathrm{P}}\left(\mathrm{T}_{1 / 2}\right), \Delta \mathrm{C}_{\mathrm{P}}{ }^{\prime}\left(\mathrm{T}_{1 / 2}\right), \mathrm{T}_{1 / 2}, \mathrm{~B}_{\mathrm{A}}, \mathrm{B}_{\mathrm{A}}{ }^{\prime}, \mathrm{B}_{\mathrm{B}}, \mathrm{B}_{\mathrm{B}}{ }^{\prime}$ in the following equations where $\mathrm{N}$ and $\mathrm{n}$ are fixed:

For the transition $\mathrm{A} \rightleftharpoons \mathrm{nB}$, the heat required to melt $\mathrm{N}$ moles is

$$
\frac{d Q}{d T}=(1-\alpha)\left(B_{A}+B_{A}^{\prime}\left(T-T_{1 / 2}\right)\right]+N\left(\frac{\Delta H_{C a l}(T)^{2}}{R T^{2}}\right) f(\alpha)+\alpha\left(B_{B}+B_{B}^{\prime}\left(T-T_{1 / 2}\right)\right]
$$

where $N_{A}$ is the number of moles of $A, N_{B}$ is the number of moles of $B$ and $f(\alpha)=\frac{\alpha(1-\alpha)}{n(1-\alpha)+\alpha}$ and $\alpha=1-\frac{N_{A, T}}{N_{A, T=0}}=\frac{N_{B, T}}{N_{B, T=\infty}}$. The free energy is determined relative to $T_{1 / 2}$ using

$$
\frac{\mathrm{K}}{\mathrm{K}_{\mathrm{T}_{1 / 2}}}=\frac{\frac{\left(\alpha \mathrm{N}_{\mathrm{B}, \mathrm{T}=\infty}\right)^{n}}{(1-\alpha) \mathrm{N}_{\mathrm{A}, \mathrm{T}=0}}}{\frac{\left(1 / 2 \mathrm{~N}_{\mathrm{B}, \mathrm{T}=\mathrm{T}_{1 / 2}}\right)^{\mathrm{n}}}{(1-1 / 2) \mathrm{N}_{\mathrm{A}, \mathrm{T}=\mathrm{T}_{1 / 2}}}}=\frac{(2 \alpha)^{\mathrm{n}}}{2(1-\alpha)}=\mathrm{e}^{-\frac{\Delta \Delta \mathrm{G}}{\mathrm{RT}}} \text { where } \alpha=1 / 2 \text { at } \mathrm{T}_{1 / 2} \text {. }
$$

$\Delta \Delta \mathrm{G}$ is determined by the following thermodynamic equations:

$$
\begin{aligned}
& \Delta H_{\text {Cal }}(T)=\Delta H_{C_{\text {all }}}\left(T_{1 / 2}\right)+\Delta C_{P}\left(T_{1 / 2}\right)\left(T-T_{1 / 2}\right)+1 / 2 \Delta C_{P}{ }^{\prime}\left(T-T_{1 / 2}\right)^{2} \quad \Delta C_{P}(T)=\Delta C_{P}\left(T_{1 / 2}\right)+\Delta C_{P}{ }^{\prime}\left(T-T_{1 / 2}\right) \\
& \frac{-\Delta \Delta G}{T}=\left(\frac{\Delta H_{C_{a l}}\left(T_{1 / 2}\right)}{T_{1 / 2}}\right)\left(\frac{T-T_{1 / 2}}{T}\right)+\Delta C_{P}\left(T_{1 / 2}\right)\left(\ln \frac{T}{T_{1 / 2}}-\frac{T-T_{1 / 2}}{T}\right)+1 / 2 \Delta C_{P}{ }^{\prime}\left(\frac{\left(T+T_{1 / 2}\right)\left(T-T_{1 / 2}\right)}{T}-2 T_{1 / 2} \ln \frac{T}{T_{1 / 2}}\right)
\end{aligned}
$$

The fitting results are shown in Figure $3 \mathrm{~B}$ for $300 \mu \mathrm{M}$ Acid-1Y. The values of the fitted parameters are as follows: $\Delta \mathrm{H}\left(\mathrm{T}_{1 / 2}\right)=132.0 \pm 0.4 \mathrm{kcal} \bullet \mathrm{mol}^{-1}, \Delta \mathrm{C}_{\mathrm{P}}\left(\mathrm{T}_{1 / 2}\right)=1.8 \mathrm{kcal} \bullet \mathrm{mol}^{-1} \bullet \mathrm{K}^{-1}$, $\Delta \mathrm{C}_{\mathrm{P}}{ }^{\prime}\left(\mathrm{T}_{1 / 2}\right)=, \mathrm{T}_{1 / 2}=356.3$. The equilibrium constant at $25^{\circ} \mathrm{C}\left(\mathrm{K}=6.1 \mathrm{X} 10^{-36}\right)$ was calculated using $\mathrm{K}(\mathrm{T})=1 /\left(\mathrm{K}\left(\mathrm{T}_{1 / 2}\right) \bullet \mathrm{e}^{-\Delta \Delta \mathrm{G} / \mathrm{RT}}\right)$, where $\mathrm{K}\left(\mathrm{T}_{1 / 2}\right)=\left(\mathrm{C}_{\mathrm{T}} / 2\right)^{\mathrm{n}} /\left(\mathrm{C}_{\mathrm{T}} / 2 \mathrm{n}\right)$ and $\mathrm{C}_{\mathrm{T}}$ is the total peptide concentration.

The van't Hoff enthalpy was calculated from the integrated calorimetric enthalpy $\left(\Delta \mathrm{H}_{\mathrm{Cal}}{ }^{*}\right)$, obtained by integrating the area between the thermogram and the baseline in Figure 5 for Zwit- 
1F and Acid-1Y. This area was used in the following equation to calculate the van't Hoff enthalpy according to Sturtevant ${ }^{5}$ and Marky and Breslauer ${ }^{6}$ :

$$
\Delta \mathrm{H}_{\mathrm{vH}}=2(n+1) \mathrm{RT}_{1 / 2}^{2} \frac{\mathrm{C}_{\mathrm{p}}^{\mathrm{Max}}}{\Delta \mathrm{H}_{\mathrm{Cal}}^{*}}
$$

where $\mathrm{C}_{\mathrm{P}}{ }^{\mathrm{Max}}$ is the maximum difference between the thermogram and the baseline heat capacity and $n$ is the number of subunits. The $\Delta \mathrm{H}_{\mathrm{vH}} / \Delta \mathrm{H}_{\mathrm{Cal}}$ ratio was calculated using the fitted $\Delta \mathrm{H}_{\mathrm{Cal}}\left(\mathrm{T}_{1 / 2}\right)$ from above.

Crystallization and Structure Determination. Acid-1Y* $(2.00 \mathrm{mM})$ was crystallized by hanging drop vapor diffusion over a buffer composed of $1.35 \mathrm{M}$ sodium citrate and $0.1 \mathrm{M}$ HEPES (pH 7.5). Crystals were cryoprotected using a step-wise transfer from mother liquor containing $0 \%$ glycerol to mother liquor supplemented with $7.5 \%$ glycerol and then $12 \%$ glycerol. X-ray diffraction data to $1.54 \AA$ resolution was collected at $100 \mathrm{~K}$ at the Yale Center for Structural Biology. Data was processed to $2.3 \AA$ resolution using the HKL2000 software suite. $^{7}$ Molecular replacement using a tetramer of the previously solved Zwit-1F octamer ${ }^{8}$ was used to obtain phases calculated to $2.3 \AA{ }^{\circ}$ using $\mathrm{CNS}^{9}{ }^{9}$ The data was determined to have partial merohedral twinning by the Yeate's twinning test with a twinning fraction ( $\alpha$ ) equal to 0.307932 \pm 0.004175 following a twin operation of 2 along $a^{*}, b^{*} .{ }^{10}$ Detwinning, density modification and NCS averaging were performed using CNS. ${ }^{9}$ The program XFIT was used to build and refine eight $33_{14}$-helices into the electron density maps. ${ }^{11}$ Refinement was preformed using CNS with an $\mathrm{R}_{\text {free }}$ set to $10 \%$ of the data. ${ }^{9}$ Pymol was used for Figure preparation. ${ }^{12}$ 
Table S1. Data collection, phasing and refinement statistics

\section{Acid-1Y*}

\section{Data Collection}

Space group

$\mathrm{P} 3_{2}$

Cell dimensions

$$
\begin{aligned}
& a, b, c(\AA) \\
& \alpha, \beta, \gamma\left({ }^{\circ}\right)
\end{aligned}
$$

$41.345,41.345,66.31$

$90,90,120$

Resolution $(\AA)$

$50-2.30(2.38-2.30)^{\mathrm{a}}$

$R$ sym or Rmerge

$10.2(33.8)$

I/ I

$17.10(3.48)$

Completeness (\%)

$99.6(96.9)$

Redundancy

$5.1(3.6)$

\section{Refinement}

Resolution ( $\AA$ )

$50-2.30$

No. reflections

10,294

$R$ work/ Rfree (\%)

$21.52 / 24.95$

No. atoms

Protein

952

Water

38

B-factors

Protein

39.758

Water

32.6549

r.m.s deviations

Bond lengths ( $\mathrm{A})$

0.005810

Bond angles $\left({ }^{\circ}\right)$

0.78714 
Deuterium Exchange NMR Studies. All spectra were acquired at $25{ }^{\circ} \mathrm{C}$ using the WATERGATE solvent suppression pulse sequence ZZPWG (see www.bruker.com for pulse sequence information). Before acquisition under the WATERGATE pulse sequence, a standard proton spectrum was acquired using a $1.5 \mathrm{mM}$ Zwit-1F sample in a 9:1 mixture of $\mathrm{H}_{2} \mathrm{O}$ and $\mathrm{D}_{2} \mathrm{O}$ and the position of the water peak was determined. ${ }^{13}$ The transmitter offset $\left({ }^{01} \mathrm{P}\right)$ was set to this frequency for ZZPWG acquisitions. Post processing was performed with a sfil type baseline correction set to $1.5 \mathrm{ppm}$ and a line broadening factor of $5.0 \mathrm{~Hz}$. In order to acquire deuterium exchange data, the Acid-1Y sample was dissolved in phosphate buffer spiked with TMSP and lyophilized. The lyophilized sample was resuspended in $\mathrm{D}_{2} \mathrm{O}$ at a concentration of $750 \mu \mathrm{M}$ just prior to insertion into the instrument. Prior to loading the Acid-1Y sample, the spectrometer was locked and shimmed on a sample of Zwit-1F in 9:1 $\mathrm{H}_{2} \mathrm{O} / \mathrm{D}_{2} \mathrm{O}$ in phosphate buffer. Amide exchange rates vary logarithmically with $\mathrm{pD}$ in the $\mathrm{EX} 2$ regime $(\mathrm{pH}<9.5$ for most $\alpha$-amino acid proteins) and therefore the $\mathrm{pD}$ of the Acid-1Y samples used in the NMR studies were carefully monitored. ${ }^{14}$ Our experiments were confirmed to belong to the EX2 regime as previously determined. ${ }^{13}$ We measured the $\mathrm{pD}$ of our Acid-1Y NMR samples after exchange was complete using a $\mathrm{pH}$ meter (Thermo Orion Model 410, Beverly, MA) in the laboratory of Prof. Ann Valentine (Yale University). The samples were determined to have values of $6.80 \pm 0.5$ and 6.87 $\pm 0.5 \mathrm{pH}$ units, which corresponds to corrected values of 7.20 and $7.27 \mathrm{pD}$ units for Acid-1Y samples 1 and 2 respectively. ${ }^{15}$ The $750 \mu \mathrm{M}$ Zwit-1F samples were also determined to have a corrected $\mathrm{pD}$ of $\sim 7.2$. Protection factors were calculated using $\mathrm{k}_{\mathrm{rc}}$ values derived from poly- $\beta$ homoglycine or using $\alpha$-amino acid dipeptides. ${ }^{13,16,17}$ The former method has been described previously; ${ }^{13}$ for the latter, we calculated $\mathrm{P}$ using $\mathrm{k}_{\mathrm{rc}}$ values values derived from all $\alpha$-amino acid dipeptides represented by the sequence of Acid-1Y $\left(\mathrm{NH}_{3}{ }^{+}-\mathrm{E}-\mathrm{L}-\mathrm{O}-\mathrm{Y}-\mathrm{L}-\mathrm{D}-\mathrm{Y}-\mathrm{L}-\mathrm{O}-\mathrm{E}-\mathrm{L}-\mathrm{D}-\mathrm{COO}{ }^{-}\right)$. 
The most conservative calculation of $\mathrm{P}$ for Acid-1Y makes reference to the $\mathrm{k}_{\mathrm{rc}}$ value for Glu-Leu; the $\mathrm{P}$ values calculated in this way vary by a factor of four from the $\mathrm{P}$ values calculated with reference to the $k_{\mathrm{rc}}$ value for poly- $\beta$-homoglycine (Table S1).

Table S1. Protection factors calculated from two kex sources, poly- $\beta$-homoglycine and $\alpha$-amino acid dipeptide (Glu-Leu)

\section{Protection Factors}

\begin{tabular}{|c|c|c|c|c|}
\hline$k_{\text {ex }}$ source & Peak A & Peak B & Peak C & Peak D \\
\hline poly- $\beta$-homoglycine ${ }^{18}$ & 59000 & 52300 & 69300 & 20500 \\
\hline \multicolumn{5}{|l|}{$\alpha$-amino acid dipeptide } \\
\hline$(\text { Glu-Leu })^{16}$ & 14000 & 13000 & 17000 & 5000 \\
\hline
\end{tabular}
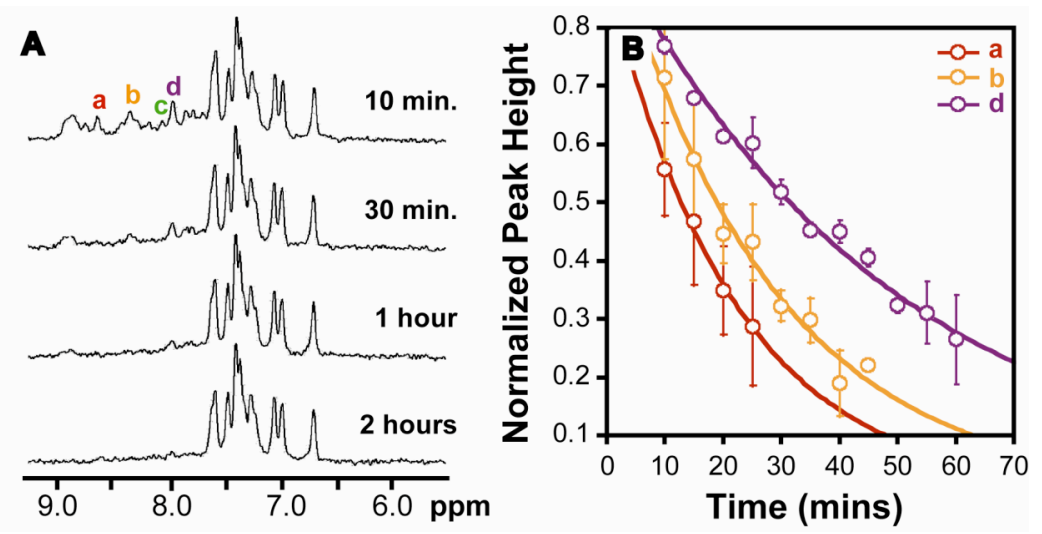

Figure S4. NMR Studies of Zwit-1F at $\quad 750 \quad \mu \mathrm{M}$ concentration. (A) $500 \mathrm{MHz}$ 1H NMR spectra of Zwit-1F acquired at the indicated times after the lyophilized Zwit-1F sample was reconstituted in phosphate-buffered $\mathrm{D}_{2} \mathrm{O}$. (B) Peak heights of the indicated resonances (plotted as normalized values to a peak at $6.39 \mathrm{ppm}$ ) are fit to exponential decays for one of the Acid-1Y deuterium exchange NMR experiments. 


\section{References}

1. Kritzer, J. A.; Tirado-Rives, J.; Hart, S. A.; Lear, J. D.; Jorgensen, W. L.; Schepartz, A., J. Am. Chem. Soc. 2005, 127, 167-78.

2. Durchschlag, H.; Zipper, P., Prog. Colloid Polym. Sci. 1994, 94, 20-39.

3. Degrado, W. F.; Lear, J. D., J. Am. Chem. Soc. 1985, 107, 7684-7689.

4. $\quad$ Kirchhoff, W. M., NIST Technical Note 14011993.

5. Sturtevant, J. M., Annu. Rev. Phys. Chem. 1987, 38, 463-488.

6. Marky, L. A.; Breslauer, K. J., Biopolymers 1987, 26, 1601-1620.

7. Otwinowski, Z.; Minor, W., Macromol. Crystal., Pt A 1997, 276, 307-326.

8. Daniels, D. S.; Petersson, E. J.; Qiu, J. X.; Schepartz, A., J. Am. Chem. Soc. 2007, 129, 1532-3.

9. Brunger, A. T.; Adams, P. D.; Clore, G. M.; DeLano, W. L.; Gros, P.; Grosse-Kunstleve, R. W.; Jiang, J. S.; Kuszewski, J.; Nilges, M.; Pannu, N. S.; Read, R. J.; Rice, L. M.; Simonson, T.; Warren, G. L., Acta Crystallogr. Sect D: Biol. Crystallogr. 1998, 54, 905-921.

10. Yeates, T. O., Macromol. Crystal. Pt A 1997, 276, 344-358.

11. McRee, D. E., J. Struct. Biol. 1999, 125, 156-165.

12. DeLano, W., The PyMOL Molecular Graphics System. DeLano Scientific: San Carlos, 2002.

13. Petersson, E. J.; Craig, C. J.; Daniels, D. S.; Qiu, J. X.; Schepartz, A., J. Am. Chem. Soc. 2007, 129, 5344-5.

14. Krishna, M. M. G.; Hoang, L.; Lin, Y.; Englander, S. W., Methods 2004, 34, 51-64.

15. Glasoe, P. K.; Long, F. A., J. Phys. Chem. 1960, 64, 188-190.

16. Bai, Y. W.; Milne, J. S.; Mayne, L.; Englander, S. W., Proteins: Struct., Funct., Genet. 1993, $17,75-86$. 
17. Glickson, J. D.; Applequi.J, J. Am. Chem. Soc. 1971, 93, 3276-\&.

18. Glickson, J. D.; Applequist, J., J. Am. Chem. Soc. 1971, 93, 3276-81. 